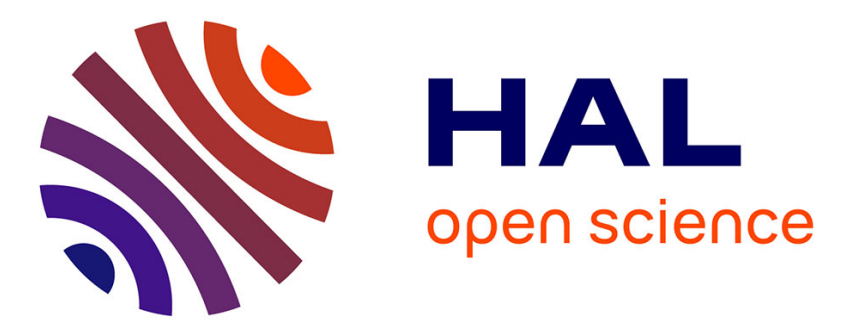

\title{
Single nano-particle flow detection and velocimetry using Optical Feedback Interferometry
}

Raul da Costa Moreira, Julien Perchoux, Yu Zhao, Clément Tronche, Francis Jayat, Thierry Bosch

\section{- To cite this version:}

Raul da Costa Moreira, Julien Perchoux, Yu Zhao, Clément Tronche, Francis Jayat, et al.. Single nano-particle flow detection and velocimetry using Optical Feedback Interferometry. IEEE Sensors 2017, Oct 2017, Glasgow, United Kingdom. 3p. hal-01685162

\section{HAL Id: hal-01685162 https://hal.science/hal-01685162}

Submitted on 26 Jan 2018

HAL is a multi-disciplinary open access archive for the deposit and dissemination of scientific research documents, whether they are published or not. The documents may come from teaching and research institutions in France or abroad, or from public or private research centers.
L'archive ouverte pluridisciplinaire HAL, est destinée au dépôt et à la diffusion de documents scientifiques de niveau recherche, publiés ou non, émanant des établissements d'enseignement et de recherche français ou étrangers, des laboratoires publics ou privés. 


\title{
Single nano-particle flow detection and velocimetry using Optical Feedback Interferometry
}

\author{
R. da Costa Moreira, J. Perchoux, Y. Zhao, C. Tronche, F. Jayat, T. Bosch \\ LAAS-CNRS, Université de Toulouse, CNRS, INP, Toulouse, France
}

\begin{abstract}
We present a sensing technique based on the Optical Feedback Interferometry (OFI) scheme in a laser diode that enables single particle detection at micro and nano-scales through the Doppler-Fizeau effect. Thanks to the proposed signal processing, this sensing technique can detect the presence of single spherical micro/nanoparticles and measure their velocity, even while their diameter is below half the laser wavelength. The method was validated with polystyrene spheres with diameter ranging from $196 \mathrm{~nm}$ to $10.14 \mu \mathrm{m}$ flowing in diluted aqueous solutions. These results indicate potential applications for the biomedical and chemical engineering fields.
\end{abstract}

Keywords-Optical Feedback Interferometry, microfluidics, velocimetry, light scattering, nanoscale sensing, Doppler effect.

\section{INTRODUCTION}

The increasing demand for technologies of nanoparticles detection and characterization in biomedical and chemical engineering applications has reached industrial processes where production quality controls of materials and products requires dedicated tools. We propose here to apply a novel interferometric method to address this problematic.

The Optical Feedback Interferometry (OFI) in a laser diode arises when part of the emitted light is back-scattered from a distant object and then reinjected into the laser cavity. This reinjected light provokes a modulation of the laser output power that carries information about the light interaction with the target. This technique scheme has been earlier proposed in many metrology applications, such as displacement [1], velocity [2] and vibration [3]. Many efforts have been made in both experimental and theoretical frame in order to extend the application domains of such a sensor [4].

In the microfluidics field, many OFI sensing techniques are capable to perform flowmetry and local velocimetry [5]-[13]; but, to the best of our knowledge, none of them performed detection in a single particle, and especially with nanoparticles. Compared to other interferometry sensing schemes, the OFI offers great advantages of compactness, self-alignment and low-cost, and less and more simple external optical elements; especially for laser diodes with built-in package photodiode. While previous works on OFI flowmetry have been limited to high particle densities fluids in single or multiple scattering regimes, the work depicted in this paper propose to investigate the feasibility for the detection and the measurement of a single nanoparticle velocity.

\section{PRINCIPLE OF OFI SENSING IN SINGLE PARTICLE REGIME}

A particle detection OFI sensor is basically a laser diode with focusing optics allowing for a sharp focus at the center of the microchannel region where a laminar flow is established as illustrated by the Fig. 1.

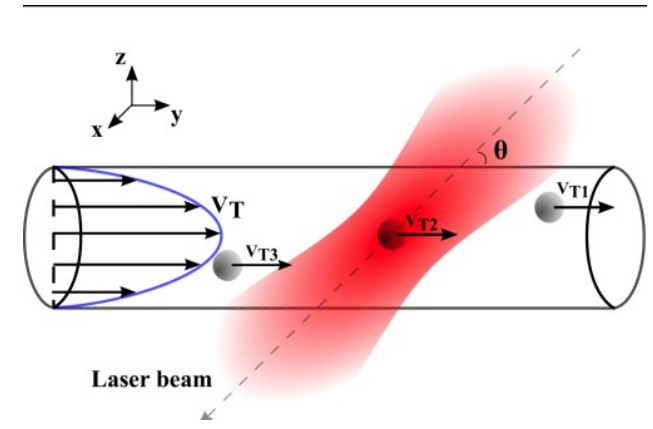

Fig. 1. OFI sensing scheme for single particle detection in a microchannel.

In OFI sensing for microfluidics applications at single particle regime, once a particle crosses the laser sensing volume with a velocity $V_{T}$, it generates a Doppler shift frequency $\left(f_{D}\right)$ of backscattered reinjected light by

$$
f_{D}=\frac{2 V_{T} \cos \theta}{\lambda},
$$

where $\lambda$ is the laser wavelength, and $\theta$ is the angle between the laser beam and the flow direction.

The dynamics of backscattering is ruled by the scattering cross-section of the particles against the laser power density of illumination, and their optical properties in the medium based on the Mie theory.

The particles are carried in a liquid pumped at constant flow rate into the channel. The particle concentration in such fluid is controlled to achieve a single particle regime which requires that just one single particle is crossing the sensing volume during each signal acquisition period. The velocity $V_{T}$ of each particle is dependent on its radial position in the duct where a laminar flow profile is established.

\section{EXPERIMENTAL SETUP}

The setup of OFI sensing used for single particle detection is represented in the Fig. 2. It is constituted by a $785 \mathrm{~nm}$ FabryPerot laser diode (Thorlabs L785P090) with a monitoring photodiode built-in package, custom made laser driver and 
transimpedance amplifier and, a focusing lens (Thorlabs C240TME-B, $8 \mathrm{~mm}$ focal length) located at twice its focal distance regarding both the laser and the axial center of the micro-channel.

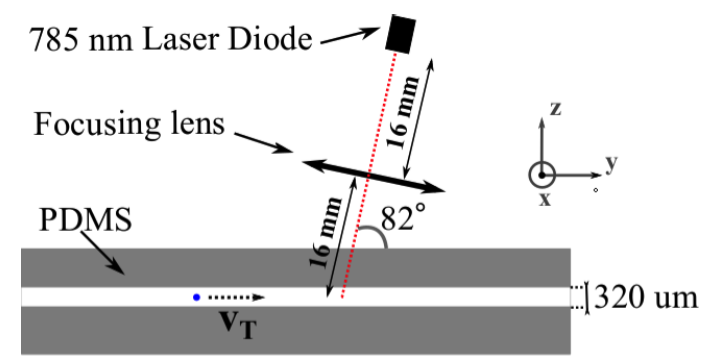

Fig. 2. OFI setup for single particle detection with $\theta=82^{\circ}$.

The microfluidic chip used in our experiments is a PDMS circular duct of $320 \mu \mathrm{m}$ diameter, and $230 \mathrm{~mm}$ length. The related Reynolds number is about 2.64, which gives a hydrodynamic entrance region corresponding to $42.24 \mu \mathrm{m}$. The OFI sensor is set on a 3-axis linear stage (Zaber Tech. TLSM100A), the laser beam was focused in the center of the micro-channel and far beyond the entrance region. In that way, the sensing volume is set over the region where the laminar velocity profile is fully developed fitting well the HagenPoiseuille profile [14] for a Newtonian fluid. For a circular cross section the maximum velocity $\left(\mathrm{v}_{\max }\right)$, corresponding to the center of the channel, is equal to $2 \mathrm{Q} / \mathrm{A}$; where $\mathrm{Q}$ is the volumetric flow rate, and $\mathrm{A}$ is the cross section area. In all experiments, the liquid was pumped at constant flow rate of $40 \mu \mathrm{L} / \mathrm{min}$ with a syringe pump (Harvard Apparatus Pico 11 Plus). The angle $\theta$ of $82^{\circ}$ is set between optical axis and the flow direction ensuring a maximum Doppler shift of $5.9 \mathrm{kHz}$ for particle in the center of the duct. Such theoretical value is obtained by (1) at $\mathrm{v}_{\max }$.

As the current of the monitoring built-in package photodiode reveals an image of the output optical power of the laser, such current is acquired by a data acquisition card (National Instruments NI-6361 USB) through the custom transimpedance amplifier.

The signal processing is written with Matlab scripts embedded in a Labview VI. The whole detection algorithm is implemented in this environment. The graphical user interface (GUI) allows to configure the detection parameters, and to monitor the process in real-time.

The detection of the Doppler signal burst is based on a threshold condition on the signal amplitude in the frequency domain. Thus it consist in a band-pass filtering, a timefrequency conversion using Matlab Pwelch algorithm (window of $2^{13}$ samples, no overlapping, and $2^{17}$ DFT points), and a thresholding that keeps signal which amplitude is at least $3 \mathrm{~dB}$ above the noise floor in the spectrum. The band-pass filter cutoff frequency are set to $1 \mathrm{kHz}$ and $8.5 \mathrm{kHz}$. The low frequency cut-off allows eliminating low-frequency perturbations. The high frequency cut-off is set based on the maximum Doppler shift expected with a $50 \%$ margin.

\section{EXPERIMENTS AND RESULTS}

For the experiments, four different aqueous dispersions of monodispersed polystyrene $\left(\mathrm{TPD}=1.05 \mathrm{~g} / \mathrm{cm}^{3}\right)$ spheres were tested. These Microparticles $\mathrm{GmbH}$ tracers are at unique controlled size with very low standard deviation (SD). The four diameters tested are: $196 \mathrm{~nm}$ (PS-R-KM10, 5\% weight/volume, $\mathrm{SD}=5 \mathrm{~nm}$ ), $552 \mathrm{~nm}$ (PS-R-L2654, 5\% w/v, $\mathrm{SD}=13 \mathrm{~nm}), 4.89 \mu \mathrm{m}$ (PS/Q-R-KM153, 10\% w/v, SD=80 nm) and $10.14 \mu \mathrm{m}$ (PS/Q-R-SC08, 10\% w/v, SD=120 nm).

From each mother solution, we prepared a solution with a particle concentration low enough to reach a single particle regime regarding the time of acquisition: respectively $0.00005 \% \mathrm{w} / \mathrm{v}$ for $196 \mathrm{~nm}$ and $552 \mathrm{~nm}$, and $0.01 \% \mathrm{w} / \mathrm{v}$ for the $4.92 \mu \mathrm{m}$ and $10.14 \mu \mathrm{m}$. The first two sample solutions were diluted with deionized water, and the micrometric ones with
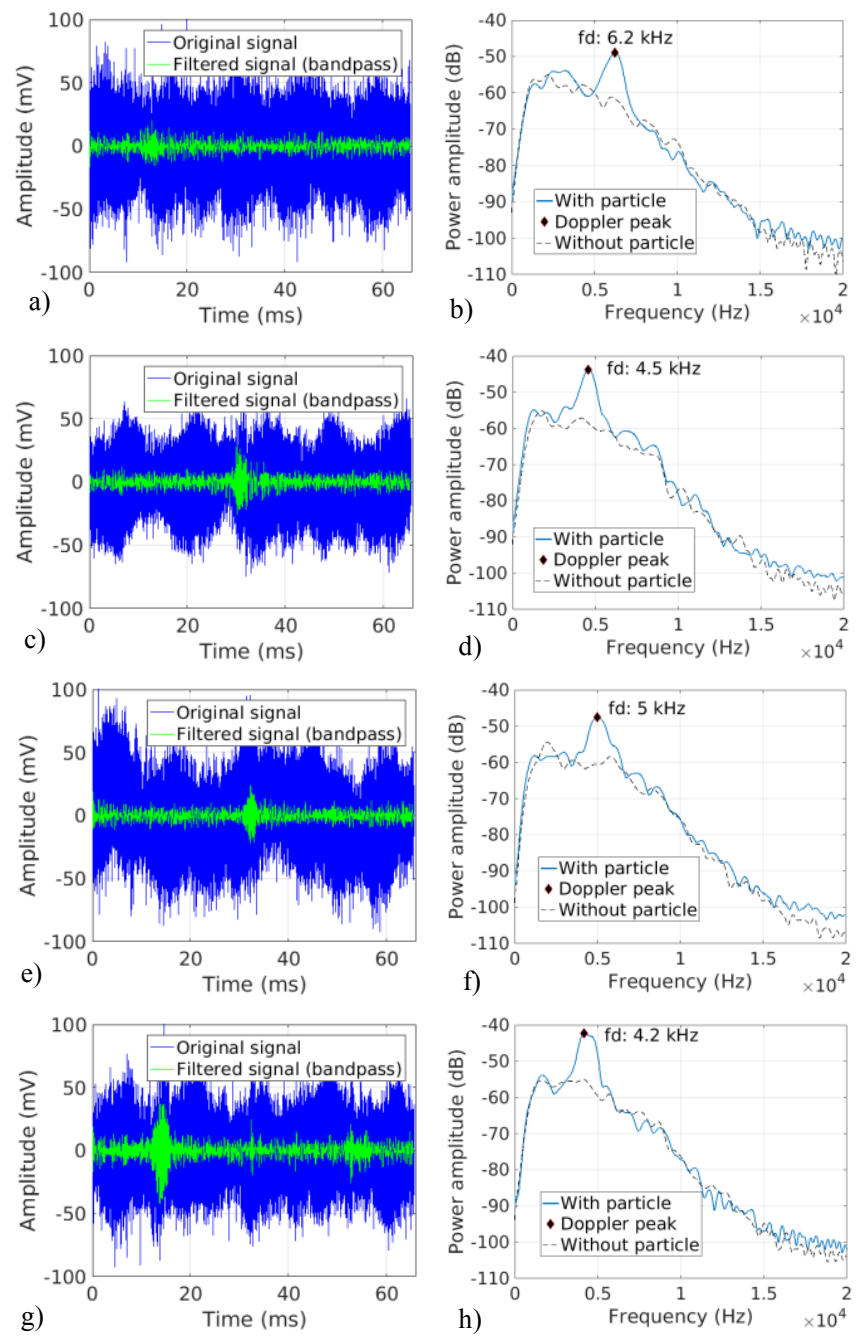

Fig. 3. OFI signals acquired with a unique PDMS particle sensing. Left column, time domain signal before (blue) and after (green) band-pass filtering; right column: filtered signal spectrum (blue solid line) compared to the sensor signal spectrum in absence of particle (black dashed line).

a) \& b) $196 \mathrm{~nm}$ particle, $f_{D}=6.2 \mathrm{kHz}$; ) \& d) $552 \mathrm{~nm}$ particle, $f_{D}=4.5 \mathrm{kHz}$; e) \& f) $4.89 \mu \mathrm{m}$ particle, $f_{D}=5 \mathrm{kHz}$; g) \& h) $10.14 \mu \mathrm{m}$ particle, $f_{D}=4.2 \mathrm{kHz}$. 
PBS (phosphate buffer solution $1.05 \mathrm{~g} / \mathrm{cm}^{3}$, by SigmaAldrich) filtered by $0.2 \mu \mathrm{m}$ membrane syringe filters.

The Fig. 3 shows an example of single particle that was automatically detected for each size. In the time domain signals, the blue and green lines represent respectively the original OFI signal and the filtered signal. In the spectra of the filtered signals, the black dashed lines correspond to the filtered signal spectrum acquired in absence of particle. These give a floor reference to be compared with the respective filtered spectrum (in blue) where there is particle detected.

To double check the purity of the used deionized water and filtered PBS against the eventual presence of spurious particles, we performed an experiment for each while maintaining the same detection parameters, no false positive was detected over 4 hours.

\section{CONCLUSION AND FUTURE WORKS}

An innovating OFI sensing scheme for detection of single particle able to address nanoscale particles is presented in this work.

Regarding other classical technologies for particle detection, the OFI technique, due to the fact that it is an optical non-invasive method, presents the benefits of higher capability of integration and compactness.

Among the main potential applications of this innovating technique, we could mention: flow cytometry; real-time cell counting; velocimetry at chemical micro-reactors for production of chemical substances and pharmaceuticals; biosensing for sickness diagnosis; detection of solid contaminants in fluid flows, like for water quality control; and also for prospections at marine science researches.

Perspectives of this approach are related to the exploitation of the burst properties in order to eventually perform particle sizing.

\section{REFERENCES}

[1] U. Zabit, O. D. Bernal, T. Bosch, and F. Bony, "MEMS accelerometer embedded in a self-mixing displacement sensor for parasitic vibration compensation," Optics. Letters, Vol.. 36,No.5, 612-614 (2011).
[2] J. Perchoux and T. Bosch, "Multimode VCSELs for self-mixing velocity measurements," in Proceedings of IEEE Conference on sensors (IEEE, 2007), pp. 419-422.

[3] S. Donati, M. Norgia, and G. Giuliani, "Self-mixing differential vibrometer based on electronic channel subtraction," Applied Optics,Vol. 45, No.28, 2006.7264-7268

[4] T.Taimre, M.Nikolić, K.Bertling, Y. L.Lim, T.Bosch and A. D.Rakić, "Laser feedback interferometry: a tutorial on the self-mixing effect for coherent sensing", Advances in Optics and Photonics, Vol. 7, No.3, 2015.570-631.

[5] C. Zakian, M. Dickinson and T. King, "Dynamic light scattering by using self-mixing interferometry with a laser diode", Applied Optics, Vol. 45, No. 10, 2006.

[6] C. Zakian and M. Dickinson, "Self-mixing interferometry with a laser diode: experimental considerations for sensing applications," IOP, Journal of Optics A: Pure and Applied Optics (2006), 8:555-568.

[7] C. Zakian, M. Dickinson and T. King, "Particle sizing and flow measurement using self-mixing interferometry with a laser diode," IOP, Journal of Optics A: Pure and Applied Optics, Vol. 7, No. 6, 2005.

[8] Y.Zhao, J.Perchoux, L. Campagnolo, T.Camps, R.Atashkhooei and V.Bardinal, "Optical feedback interferometry for microscale-flow sensing study: numerical simulation and experimental validation", Optics Express, Vol. 24, No 21, 2016. 23849-23862.

[9] Chirstian M. Zakian and Mark R. Dickinson,"Flow measurements through scattering samples using self-mixing interferometry with a laser diode", SPIE, Vol. 6191, 619117-1, 2015.

[10] Kenju Otsuka, Kazutaka Abe, Natsumi Sano, Seiichi Sudo and JingYuan Ko, "Two-chanel self-mixing laser Doppler measurement with carrier-frequency-division multiplexing", Applied Optics, Vol. 44, No.9,2005.

[11] Seiichi Sudo, Yoshihiko Miyasaka and Kenu Otsuka, "Quick and easy measurement of particle size of Brownian particles and plankton in water using self-mixing laser", Optics Express, Vol. 14, No. 3,2006.

[12] S. Sudo, Y. Miyasaka, K. Nemoto, K. Kamikariya and K. Otsuka, "Detection of small particles in fluid flow using a self-mixing laser", Optics Express, Vol. 15, No. 13,2007.

[13] Bernat, J.J. Gonzalez-Murillo, L. Fonseca, M. Moreno, A. RomanoRodriguez, "Optical particle detection in liquid suspensions with a hybrid integrated microsystem", Sensors and Actuators A 247, 2016.

[14] L. Campagnolo, M. Nikolic, J. Perchoux, Y. L. Lim, K. Bertling, K. Loubière, L. Prat, A. D. Rakic, and T. Bosch, "Flow profile measurement in microchannel using the optical feedback interferometry sensing technique," Microfluidics and Nanofluidics (2013), 14:113119 . 